\title{
Access to kidney transplantation: a bioethical perspective
}

\author{
Bruno A Lima ${ }^{1}$, Helena Alves ${ }^{2}$ \\ ${ }^{1}$ Oficina de BioEstatistica, Ermesinde \\ 2 Instituto Nacional de Saúde, Dr Ricardo Jorge, Porto
}

\section{BACKGROUND}

When possible, kidney transplantation is the best renal replacement treatment for end stage renal disease patients. Indeed, compared to dialysis, kidney transplantation has better survival outcomes, its costs are lower, and patients' quality of life increases substantially ${ }^{1}$. Unfortunately, kidneys from deceased donors for transplantation are scarce, and their availability falls far short of the needs of wait-list patients.

Striking a balance between fairness and utility in the distribution of a scarce good such as deceased donors' kidneys (DDK) for transplantation has long been a challenge and a goal for many organizations that bear responsibility for defining organ allocation systems ${ }^{2}$. Moreover, when managing access to kidney transplantation from deceased donors, a balance is sought between optimizing the transplant's clinical outcome (principle of utility) and giving all patients a reasonable opportunity to receive a transplant (principle of justice) ${ }^{3}$. The aim is to find a form of distribution that is equitable, in terms of both horizontal equity (treating equals equally) and vertical equity (treating differently what is different).

For the occasion of the $10^{\text {th }}$ anniversary of the adoption by the General Conference of the United Nations Educational, Scientific and Cultural Organisation (UNESCO) of the "Universal Declaration on Bioethics and Human Rights" 4 , Petrini addressed the necessity for considering the principles in the Declaration on policies concerning the allocation of organs ${ }^{5}$. The author highlighted, among the principles laid down in the declaration: benefit and harm (Article 4), equality, justice and equity (Article 10), nondiscrimination and nonstigmatization (Article 11), solidarity and cooperation (Article 13), social responsibility and health (including access to quality healthcare; Article 14), and sharing of benefits (Article 15); as those most relevant for the allocation of organs ${ }^{5}$.

When donation is not expressed and directed to someone in particular, organs for transplantation can be seen as property of wait-list patients as a whole. Further, the State, as regulator, has the obligation to ensure, for each available organ for transplantation, an impartial choice of organ receptor ${ }^{6}$. Under the ethical principle of fairness, equals should be treated equally so that all patients have an equal opportunity to access transplantation. Conversely, given utilitarian values, some inequalities may be allowed if doing so gives society - as a group - the greatest benefit through maximizing the utility of resources. Therefore, kidneys from deceased donors may be directed to those patients who can best use them and are less likely to return to waiting lists due to graft rejection.

\section{EQUAL OPPORTUNITY MATRIX}

Given the limitations on health resources and the consequent need for them to be distributed equitably, in 1998, Daniels and Sabin proposed the concept of "accountability for reasonableness"7, whereby decisions about the allocation of limited and scarce resources must not only be made publicly but should seek to satisfy people's perceptions of appropriate healthcare. To accomplish this goal, verification of "accountability for reasonableness" relies on 4 conditions:

- Publicity condition - Decisions on the implementation of new health policies and the reasons behind these decisions should be made public.

- Relevance condition - The rationale behind these decisions must be supported by solid evidence and principles whereby all stakeholders (managers, health professionals and patients) can reach consensus, considering the needs of their target populations and the inevitable need for cost containment given scarce assets.

- Appeals condition - A mechanism should be established for challenging decisions made and for revising those decisions whenever there is new evidence or argumentation that justifies doing so.

- Regulative condition - This process should be regulated assuring that the three previous conditions are fulfilled.

Daniels' distributive proposal ${ }^{7}$ assumes the need to make a binary choice between acceptable and superfluous healthcare, discerning between health needs (i.e., healthcare required for typical functioning) and health preferences (where convenience is prioritized beyond what is reasonably normal). Additionally, Nunes and $\operatorname{Rego}^{8}$ proposed a form of healthcare distributive justice designated as the Equal Opportunity Function ((EO) F) - a complementary approach to Daniels's proposal. In (EO)F, authors consider both a hierarchy of needs, in agreement with Maslow's pyramid ${ }^{9}$, and the financial constraints imposed by the public health system. With this proposal, it is possible to adjust the available healthcare resources to the financial means of a society at a given time, always ensuring a minimum of healthcare for the entire population. Furthermore, as the authors reported, an iniquity (treating two people unfairly) may be ethically acceptable if this treatment is due to restrictions imposed by the system as stated by (EO)F, if and only if this inequality does not undermine the basic rights of the people and the decision that gave rise to it has been taken according to Daniels' 4 conditions for "accountability for reasonableness". In fact, those four conditions legitimize health choices made through the application of $(E O) F^{8}$. In a linear way, we can transpose (EO)F to an equal opportunity matrix ((EO)M) as described in Table 1. In this (EO)M, for each row we 


\section{Table 1}

Equal opportunity matrix (EO)M.

According to the financial capability, Maslow's needs are ranked in the upper half of the matrix

\begin{tabular}{|c|c|c|c|c|c|c|}
\hline & $\$$ & $\$ \$$ & $\$ \$ \$$ & $\$ \$ \$ \$$ & $\$ \$ \$ \$$ & $\$ \$ \$ \$ \$$ \\
\hline Physiological needs & $1^{\text {st }}$ & $1^{\text {st }}$ & $1^{\text {st }}$ & $1^{\text {st }}$ & $1^{\text {st }}$ & $1^{\text {st }}$ \\
\hline Safety needs & - & $2^{\text {nd }}$ & $2^{\text {nd }}$ & $2^{\text {nd }}$ & $2^{\text {nd }}$ & $2^{\text {nd }}$ \\
\hline Love and belonging & - & - & $3^{\text {rd }}$ & $3^{\text {rd }}$ & $3^{\text {rd }}$ & $3^{\text {rd }}$ \\
\hline Esteem & - & - & - & $4^{\text {th }}$ & $4^{\text {th }}$ & $4^{\text {th }}$ \\
\hline Self-actualization & - & - & - & - & $5^{\text {th }}$ & $5^{\text {th }}$ \\
\hline Self-transcendence & - & - & - & - & - & $6^{\text {th }}$ \\
\hline
\end{tabular}

Each $\$$ represents an amount of money in a healthcare system.

have Maslow's hierarchy of needs and in each column we have different levels of available resources represented by the financial capability of the health system. The upper half of (EO)M have the rank of mandatory Maslow needs for the public service according to the financial availability of the system (i.e. by column). The dilemma health systems face is to articulate, in a fair and impartial manner, the right of access to healthcare, using the available resources in society.

The previously proposed kidney allocation color system ${ }^{10,11}$, can be seen from the point of view of justice as a practical example of the application of (EO)M: patients on the waiting list are prioritized by the criteria of clinical urgency (red group) and then by waiting time or because they are less likely to be transplanted (those who remain on dialysis the longest are in the poorest health). However, all listed patients are always considered for transplantation, achieving a systematic and fair solution for the distribution of DDK (Table 2).

\section{$\underline{\text { Table } 2}$}

Kidney allocation color system ${ }^{10}$

\begin{tabular}{|c|c|c|c|c|}
\hline & Not ECD & & ECD & \\
\hline \multirow{4}{*}{ 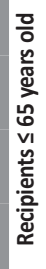 } & Clinically Urgent & RED & Clinically Urgent & \\
\hline & $\begin{array}{l}\text { CPRA } \geq 85 \% \\
\text { or ToD } \geq 3 \text { rd Quartile * }\end{array}$ & ORANGE & $\mathrm{CPRA} \geq 85 \%$ or ToD $\geq 3$ rd Quartile * & \\
\hline & $\begin{array}{l}\text { CPRA } \geq 50 \% \\
\text { or ToD } \geq \text { Median * }\end{array}$ & YELLOW & CPRA $\geq 50 \%$ or ToD $\geq$ Median * & \\
\hline & $\begin{array}{l}\mathrm{CPRA}<50 \% \\
\text { and ToD }<\text { Median* }\end{array}$ & GREEN & CPRA $<50 \%$ and ToD $<$ Median * & \\
\hline
\end{tabular}

ECD - Extended Criteria Donor; cPRA - calculated PRA;

ToD - Time on dialysis

* - wait-list patients' time from first dialysis to transplantation

The right of access to healthcare is crucial to provide effective equal opportunities in a free and inclusive society ${ }^{12}$. Further, this right must be interpreted from the point of view of egalitarian theories (i.e., equally fair opportunities for all) but also from a utilitarian point of view, once the benefit, utility and effectiveness associated with healthcare costs must be analysed. Similarly, scarce health resources, such as organs for transplantation, should be used to ensure the effectiveness of treatments and the least possible waste. As noted by Nunes et al. ${ }^{12}$, a universal right of access to healthcare must be based on three principles: equal opportunity; solidarity; and evidence-based practice. By the same token, in the case of access to DDK for transplantation, an organ allocation system should ensure that all wait-list patients have a real opportunity of being transplanted; fair access to organs is ensured; and that organ distribution rules take into consideration the best available scientific evidence.

\section{EVIDENCE BASED DECISION MAKING}

As Sackett put it ${ }^{13}$ : "Evidence based medicine is the conscientious, explicit, and judicious use of current best evidence in making decisions about the care of individual patients". Indeed, evidence based medicine (EBM) practice translates into combining the clinician's experience with the best evidence from quality clinical research and considering the patient's values, expectations and context. Through EBM, it is possible to identify and apply not only the most effective but also the most efficient treatments to maximize the amount and quality of patient health. Thus, EBM can and should also be used to allocate health resources ${ }^{14}$.

The use of EBM in clinical practice is based on the ethical principles of beneficence, nonmaleficence and respect for the autonomy of the person as part of the clinical process. Notwithstanding those principles, EBM can be extended to include healthcare policy decision making, public health and population-based decision making. This extension of EBM we call Evidence Based Decision Making (EBDM). Likewise, EBDM is a key tool in the distribution of public health resources (such as the allocation of DDK) that, based on both egalitarian and utilitarian values, can ensure that decisions are supported by the best available scientific evidence. Using EBDM in the distribution of scarce resources at a macro level also implies the application of Daniels' four conditions for the "accountability for reasonableness"7. Thus, the application of EBDM in the definition of kidney transplant allocation rules also safeguards that the rules defined for the allocation of deceased organ donors must guarantee the best predictable results based on existing scientific evidence.

In addition, if EBM's primary goal is to increase scientific knowledge and consequently to increase the quality of the healthcare provided, a second goal will be to ensure that scarce health resources are allocated fairly in treatments of proven clinical value ${ }^{14}$. In accordance with the EBM paradigm, an objective application of distributive justice requires that scarce health resources must be used in treatments of proven effectiveness. Therefore, EBM allows the prioritization of healthcare based on effectiveness, ensuring fair access to that healthcare. Furthermore, as stated by Nunes et al. ${ }^{12}$, efficiency in health resource allocation should be seen as an ethical imperative. The combination of Daniels' "accountability for reasonableness" and Nunes' (EO)F principles will allow us to define, in a fair and transparent manner, the best criteria to take into account when allocating a scarce good such as DDK for transplantation ${ }^{12}$.

\section{CONCLUSION}

To substitute current Portuguese rules for donor-recipient selection in kidney transplantation, in force since 2007, we should try to find a simpler, more transparent and fairer kidney allocation system ${ }^{11}$. The 
need to define new rules to replace current ones has been recognized for a long time ${ }^{10,15,16}$. In conclusion, the application of (EO)M principles, with the four conditions of "accountability for reasonableness" will guarantee the process legitimacy in defining the necessary new rules; it will also guarantee the fairness of the obtained results.

\section{References}

1. Medin C, Elinder C, Hylander B, Blom B, Wilczek H. Survival of patients who have been on a waiting list for renal transplantation. Nephrol Dial Transplant. 2000;15:701-704.

2. Randal Bollinger R, Cho WH. Organ allocation for transplantation in the USA and Korea: The changing roles of equity and utility. Yonsei Med J. 2004;45(6):1035-1042.

3. Geddes CC, Rodger RSC, Smith C, Ganai A. Allocation of deceased donor kidneys for transplantation: Opinions of patients with CKD. Am J Kidney Dis. 2005;46(5):949-956.

4. UNESCO. Universal Declaration on Bioethics and Human Rights. United Nations Educational, Scientific and Cultural Organization (UNESCO). http://www.unesco.org/new/en/social-and-human-sciences/themes/bioethics/bioethics-and-human-rights/. Accessed January 7, 2020.

5. Petrini C. Organ allocation policies 10 years after UNESCO's Universal Declaration on Bioethics and Human Rights. Transplant Proc. 2016;48(2):296-298.

6. Mendes A, Alves H. Organ Donation by Presumed Consent: Consequences and Duties to the Society that Legalizes it. In: Land W, Dossetor J, eds. Organ Replacement Therapy: Ethics, Justice, Commerce. Berlin: Springer-Verlag; 1991:280-283.
7. Daniels N, Sabin J. The ethics of accountability in managed care reform. Health Aff. 1998;17(5):50-

8. Nunes R, Rego G. Priority setting in health care: A complementary approach. Heal Care Anal. 2014;22(3):292-303.

9. Maslow A. A theory of human motivation. Psychol Rev. 1943;50:370-396.

10. Lima BA, Mendes M, Alves H. Kidney transplant allocation in Portugal. Port J Nephrol Hypert. 2013;27(4):313-316.

11. Lima BA, Alves H. Selection of donor-recipient pairs in renal transplantation: Comparative simulation results. Acta Med Port. 2017;30(12):854-860.

12. Nunes R, Nunes SB, Rego G. Health care as a universal right. J Public Heal. 2017; 25(1): 1-9.

13. Sackett DL, Rosenberg WMC, Gray JAM, Haynes RB, Richardson WS. Evidence based medicine: what it is and what it isn't. BMJ Br Med J. 1996;313:71-72.

14. Nunes R. Evidence-based medicine: A new tool for resource allocation? Med Health Care Philos. 2003;6(3):297-301.

15. Fonseca NM, Nolasco F. Kidney allocation: New contributions to an ongoing challenge. Acta Med Port. 2017;30(12):833-834.

16. Sampaio S. The Portuguese kidney transplant allocation system - A change is needed. Port J Nephrol Hypert. 2018;32(December):365-366.

\section{Correspondence to:}

Bruno A Lima

Oficina de Bioestatística

Rua Miguel Bombarda, 681, 10 Centro Frente, 4445-509 Ermesinde

E-mail: balima78@gmail.com 